\title{
정출연의 국방과학기술 발전 협력방안 \\ A Study on the Cooperation to develop Defence Science and Technology of GSRI
}

\author{
장대성 ${ }^{*, 1)}$ \\ Daisung Chang*,1) \\ [ 초 록 ]
}

대표적 공공연구기관으로 국가성장을 위한 혁신성과 창출의 핵심역할을 담당하는 과학기술분야 정부출연연구기관(이하 정출연)이 최근 4차 산업혁명 기술 등 혁신적인 민간기술의 군 활용을 활성화하여 국방과학기술을 더욱더 발전시켜 나아가기 위한 협력방안을 제시하였다.

\section{[ ABSTRACT ]}

As a representative public research institute, a government-funded research institute in the field of science and technology (Jung Jeon-yeon), which plays a key role in creating innovative results for national growth, recently promoted the military use of innovative private technologies such as the 4th Industrial Revolution technology to promote defense science and technology. A cooperative plan for development was suggested.

Key Words : 정출연(Public research institute), 민군기술협력(Civil-military technical cooperation), 연구개발(R\&D), 스핀온 (Spin-On), 국방과학기술(Defense Science and Technology)

\section{1. 서 론}

현대전에서는 첨단 무기체계가 군사력을 좌우하며 과학기술 경쟁력이 국방 안보와 직결된다는 인식 하에, 정부는 무기체계 개발 등을 위한 국방 R\&D에 투자를 확대하고 있다.

* 정부 국방R\&D 투자(집행액 기준) : ('15)2.44조 원 $\rightarrow$ ('17)2.78조 원 $\rightarrow(' 19) 3.23$ 조 원

정부의 국방관련 $\mathrm{R} \& \mathrm{D}$ 정책은 국방개혁 2.0 에서 국방 $\mathrm{R} \& \mathrm{D}$ 역량 강화와 방위산업 경쟁력 확보를 위한 효율적 국방획득체 계로 개선을 추진 방향으로 설정하였다. 이를 위해 최근 범정 부 차원에서 민간의 우수한 기술을 국방분야에 활용해야 한다 는 공감대가 확산되고 있다.

\section{2. 국가 R\&D 투자와 국방 R\&D 투자 간의 연계}

우리나라 정부 $\mathrm{R \& D}$ 투자의 효율성을 제고하기 위한 방안에 대한 2011년 한국개발연구원 연구보고에 따르면, 국가 $\mathrm{R} \& \mathrm{D}$ 투자와 국방 R\&D 투자 간의 연계 강화를 통해 투자 효율성을

1) 한국표준과학연구원 정책전략부 (Division of Policy and strategy, Korea Research Institute of Standards and Science)

${ }^{*}$ Corresponding author, E-mail: sung4996@gmail.com Copyright (c) The Korean Institute of Defense Technology Received: May 6, 2020

Accepted: May 25, 2020
제고하기 위한 방안에 대한 연구가 수행되었으며, 국가 R\&D 사업 효율성 제고 방안의 기본 추진방향으로 국방예산체계 개선, 국가연구개발 성과 활용을 위한 민군협력 인터페이스 확대 및 국가연구개발사업의 목표지향성 (mission-orientation) 강화방안이 제안되었다. ${ }^{[1]}$

국가연구개발사업의 목표지향성 강화방안을 단기 추진과제 와 중기 추진과제로 구분하였으며, 단기 추진과제로는 다음과 같으며

ㅇ국가연구개발사업의 군적용가능성 현황 분석

엉부출연연 신규 과제의 민군겸용성(dual-use) 강화

O과학기술분야 중기계획의 민군기술협력 수정보완 방안 추 진

웅기청 “구매조건부 신제품개발사업”의 확대 추진

이는 국가 $\mathrm{R} \& \mathrm{D}$ 투자와 국방 $\mathrm{R} \& \mathrm{D}$ 투자 간의 연계 강화 중요 성을 두각시킴은 물론 정출연의 국방과학기술 발전에 적극적 인 참여가 제시되었다.

\section{3. 국과위, 민·군 $\mathrm{R} \& \mathrm{D}$ 협력 추진계획(안)}

국가과학기술위원회(국과위)는 2012년 11월 15일 제5차 민. 군 기술협력 특별위원회(민·군특위)를 개최하고 「민·군 $\mathrm{R \& D}$ 협 력 추진계획(안)」을 보고하였다.

동 추진계획에서 가장 중점을 두고 있는 부분은 민·군의 특 
화된 강점을 상호 활용할 수 있는 민·군 융합연구 시스템 구축 이었으며, 주요내용은 '민·군 융합연구를 위하여 관련부처, 양 연구회 소관 출연(연), 국방과학연구소(이하 국과연) 등을 연계 하는 개방형 민·군 융합연구체계*를 구축함으로써 융·복합 연구 수행을 위한 시스템을 정립할 방침이다'이었다.

* 민.군특위 - 민군융합조정위원회 - 양 연구회 및 국 과연(민군기술협력지원단) - 정부출연연연구원(이하 정출연)

\section{4. 국방 $\mathrm{R} \& \mathrm{D}$}

\section{1 국방력 강화위한 과학기술 협의체 구성}

2017년 12월 '과학기술 기반 국방역량 강화를 위한 과학기술정보통신부-국방부간 업무협약' 체결 시 논의됐던 과 학기술분야 연구기관 협의체가 실현된 것으로, 6 개 연구기관 (ADD, 한국과학기술연구원, 한국기계연구원, 한국전자통신연 구원, 한국항공우주연구원, 한국원자력연구원)이 미래 국방력 확보를 위한 기관 간 업무협약을 체결함으로써 연구기관장 협 의회가 2018년 1월 발족되었다.

이 협약은 각 분야의 전문 연구기관과 국방과학기술 전문기 관이 모여 '기술 수요 발굴 - 연구개발 - 활용'으로 이어지는 연 구개발 협력 플랫폼을 구축한 것이었다.

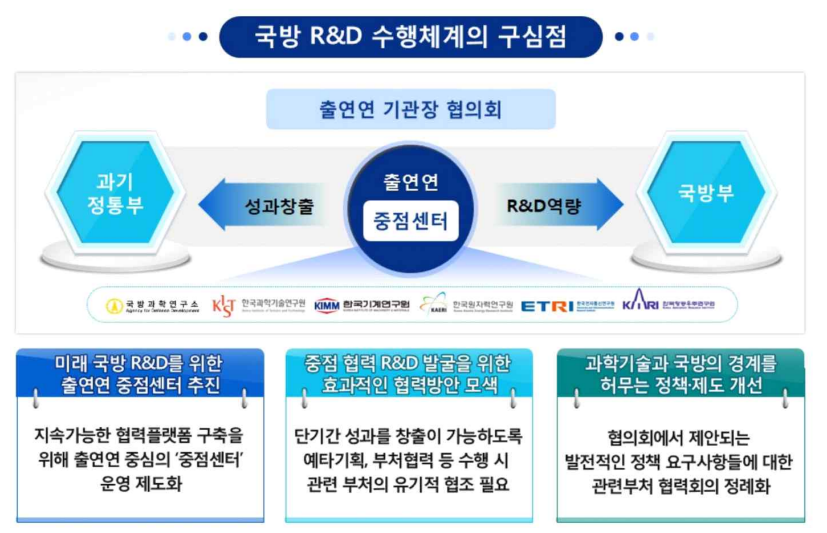

그림 1. 프로모션 계획

Fig. 1. Promotion plans

4.2 미래 국방력 확보를 위한 협력의 장 마련

과학기술을 활용한 국방R\&D에 뜻을 모은 연구기관장 협의 회는 2018년 창립된 이래 기관장 간 모임과 실무협의회를 수 차례 개최하며 실질적인 협력 방안 모색을 위해 노력해왔다. 특히 이번 행사는 연구기관장 협의회가 개최된 이후 국방 $\mathrm{R \& D}$ 대상 콘텐츠 발굴과 가시적인 성과 창출을 위한 참여기 관별 연구개발 현황 공유의 장 기획을 결정한 후 마련된 첫 번째 자리였다.

4.32018 글로벌 기계기술 포럼(2018 Global Forum on Mechanical Engineering)

4차 산업혁명 시대를 맞아 과학기술로 미래 국방력을 강화 하는 방안을 논의하는 자리가 9월 5일 마련되었다. 이날 포럼 은 '과학기술 기반 미래 국방력 강화'를 주제로 4차 산업혁명
기술에 기반한 미래 국방기술의 발전 방향부터 미국 해군의 연구개발 체계, 미래 국방력 강화를 위한 연구기관 협력 방안 까지 심도깊은 논의가 이뤄어졌다. ${ }^{[2]}$

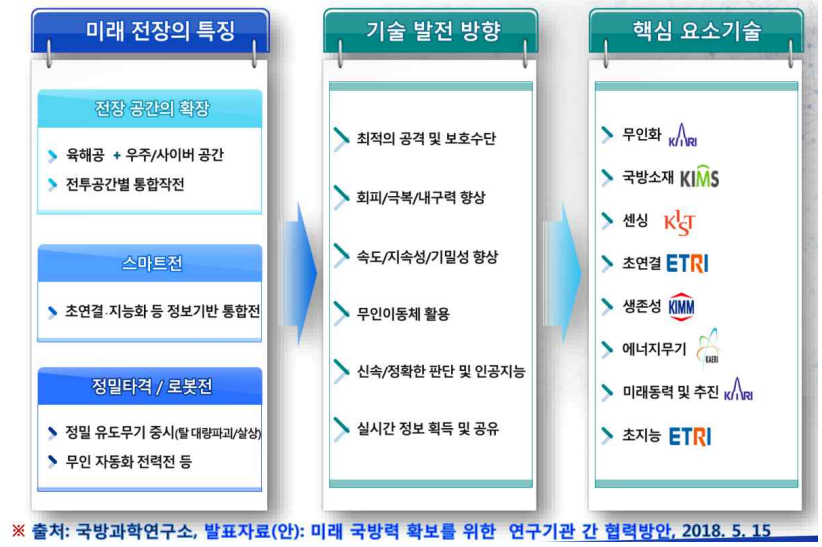

그림 2. 핵심 요소기술

Fig. 2. Core element technology

표 1. 국방 협력의 강점과 분야

Table 1. Strengths and fields of defense cooperation

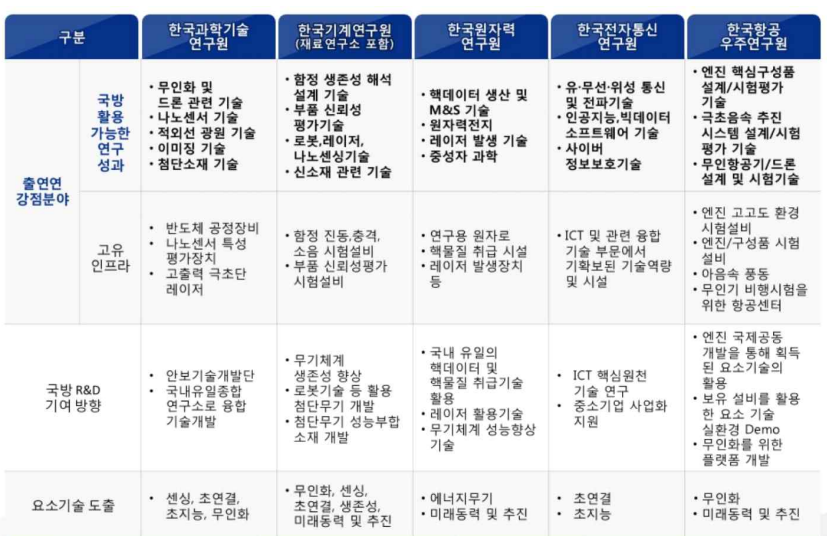

\section{4 과학기술 기반 미래국방 발전전략}

2018년 8월, 과학기술정보통신부와 국방부 및 방위사업청은 첨단 국방기술 발전의 새로운 패러다임을 제시하는 『과학기술 기반 미래국방 발전전략』을 추진한다고 밝혔다. 이번 전략은 저출산 등 사회변화로 병력규모의 감소가 예상되고 4차 산업 혁명 등 기술변화의 영향으로 이전과는 다른 양상으로 전개될 미래 국방환경에 첨단 과학기술을 통해 대응하기 위해 마련되 었다.

그동안의 협력을 통해 마련된 “미래국방 발전전략”은 첨단 과학기술이 주도할 미래전장에 대비하여 혁신적인 미래국방기 술을 개발하는 과학기술-국방 협력의 기본 틀로서, 미래선도, 중점협력, 혁신국방의 3 개의 협력 분야를 설정하고, 혁신의 기 반으로서 협력생태계를 구축하는 데에도 적극 노력하기로 하 였다. 


\section{5. 민군 기술협력}

최근 국가연구개발 예산을 효율적으로 활용하고, 민 · 군간 기 술협력 활성화를 위하여 국가과학기술연구회 소관 정출연 등 민간연구기관이 보유하고 있는 우수 기술을 무기체계에 활용 해야 한다(Spin-On)는 공감대가 확산되고 있다

민군기술협력사업은 1999년부터 시작된 대표적인 범부처 협 력 사업으로, 국방 분야 무기체계 성능 향상뿐만 아니라 민간 분야 미래 성장동력 산업의 견인에도 기여해 오고 있다.

\subsection{2년 '제1차 민·군 기술협력 기본계획(13 '17)' 수립}

본 기본계획은 지난 ' 10.10 월 수립된 "민·군기술협력 활성화 방안”에 따라 민군기술협력 중장기 계획 성격으로 ' 12.9 월 수 립된 것이었다.

본 기본계획에서는 민군기술협력사업 범위 확대, 전담기구 설치 및 전략기술로드맵 작성 등 그 동안의 민군겸용기술사업 을 민군기술협력사업으로 확대 개편하기 위한 여러 개선과제 가 마련되었다.

\section{2 민·군기술협력사업 촉진법 개정}

'13.6월「민·군기술협력사업 촉진법」으로 개정되었고 ' 14.2 월 본격 시행됨으로써 이제 민군기술협력사업은 실질적인 범 부처 협력사업으로서의 위상을 확보할 수 있는 제도적 기반이 마련되었다.

민군기술협력사업은 2014년 11개 부처가 참여하도록 확대 되었고 그 중 미래창조과학부(이하 미래부), 산업부 및 방사청 이 각자 동 사업의 추진과 관련하여 주요한 역할을 담당하고 있었다.

\section{3 제 2 차 민·군기술협력사업 기본계획(案)}

한정된 국가 연구개발예산의 효율적 활용을 위해 민군간 기 술협력 활성화 정책 기조가 확대되고 있고, 무기획득 의사결정 과정에서 투명성 제고가 필요하다는 인식이 확산되었으며, 지 난 " 14 년 수립된 국방과학기술진흥정책서에서는 민·군기술협 력 활성화 정책의 일환으로 정출연과의 연구개발 협력을 확대 하였고, 민간 보유 우수기술의 국방연구개발 활용을 증대할 것 임을 수립한 바 있었다. 18 년 2 월에 수립된 제 2 차 민군기술협 력사업에서는 $\mathrm{ADD}$ 와 과학기술분야 정출연 간 지적재산권의 공동활용을 추진할 것임을 수립하는 등 무기체계 개발 시 정 출연 등이 보유하고 있는 우수 기술을 활용하고자 하는 개선 노력이 이루어졌다.

\section{4 민군기술협력사업 2020년도 시행계획」서면심의}

산업통상자원부, 과학기술정보통신부, 방위사업청 등 14 개 부처는 2020년 3월 4일 민군기술협의회를 통해 '민군기술협력 사업 2020년도 시행계획'을 서면 심의·확정하였다.

이번 계획에 따라 정부는 올해 총 1,772 억원을 4 차 산업혁 명 핵심기술개발(로봇, 드론, $3 \mathrm{D}$ 프린팅, $\mathrm{AR}$ (증강현실) $\mathrm{MR}$ (혼합 현실)· $\mathrm{VR}$ (가상현실) 등)에 집중 투자하고, 그 개발 성과를 국방 분야에 적용함으로써 첨단 국방 구현과 신산업 경쟁력 확보를
지원해 나갈 예정이었다.

5.5 민군기술협력사업 2021년도 민·군기술협력사업 시행계 획 확정·발표

산업통상자원부, 과학기술정보통신부, 방위사업청 등 14 개 부처는 2021년 3월 18일 민군기술협의회를 통해 2021년도 민·군기술협력사업 시행계획을 확정·발표하였다.

이번 계획에 따라 정부는 올해 총 2,059억원을 투자하며, $\mathrm{IoT}$, 빅데이터, 증강현실(AR) 등 4차 산업혁명 핵심기술에 대 해 부처간 공동연구개발(다부처연계)을 추진하고, 국방분야 활 용(Spin-on)을 통해 실증기록(Trackrecord)을 확보해 나갈 예정이다

또한 신속 과제기획 제도(패스트트랙)*를 통해 지원하고, 4 차 산업혁명 민간 우수기술의 국방적용(Spin-on)을 신속히 지 원할 예정이다.

\section{6. 민군 부처연계협력기술개발사업}

정부R\&D 자원의 계획적·전략적 배분 및 투자효율성 제고를 위해 민·군 겸용이 가능한 분야를 발굴해서 민군부처 공동기획 및 기술개발

6.1 부처연계협력사업 추진근거 마련('14.2, 촉진법)

민군기술협력 사업유형 확대 : 4 개 $\rightarrow 8$ 개(부처연계협력사업 등 세부유형 추가)

(1)기술개발사업(민·군겸용기술개발, 부처연계협력기술개발, 무기체계 등의 개발, 전력지원 체계개발), (2)기술이전사업(적용 연구, 실용화연계) (3)규격표준 사업, (4)기술정보교류사업

참여부처 확대 : 4 개(산업부,방사청,미래부, 국방부) $\rightarrow 11$ 개(문 체부, 국토부, 복지부,해수부, 중기부, 기상청,소방청 추가 $\rightarrow 14$ 개, 경찰청, 해경청, 농진청 신규 참여)

6.2 '21년 착수 부처연계협력기술개발사업 발굴·기획 추진계 획(안)

2019년 3월, 민 군이 상호 win-win할 수 있는 기술을 발굴 하고, 기획단계부터 성과목표 및 부처간 역할분담을 명확히 하 여 기술협력 성과 제고

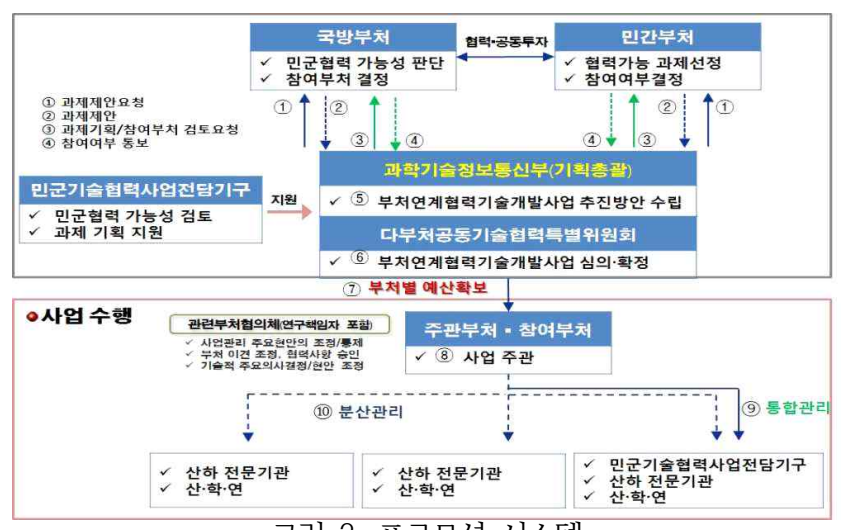

그림 3. 프로모션 시스템

Fig. 3. Promotion system 


\section{7. 정출연 보유기술의 군 적용 활성화 방안 ${ }^{[3]}$}

다음과 같은 다양한 걸림돌로 인해 아직까지 정출연이 국방 연구개발사업에 참여하여 보유하고 있는 4차 산업혁명 관련 기술 등 원천기술을 국방분야에 적용하는 사례가 미미한 실정 이다.

표 2. 정출연의 국방사업 참여 저해요인 및 보완방향 Table 2. Hindrance factors to GSRI's participation in defense projects and directions for supplementation

\begin{tabular}{|c|c|c|c|}
\hline \multicolumn{4}{|c|}{ 정출연의 국방사업참여저해요인 및 보완방향 } \\
\hline 주요 저해요인췌 & 정출연 연구자의 주요 답변 내역효 & & 향후 보완방향 \\
\hline 늦은 사업착수 & - 개발필오성과 시급성에도 불구하고 착수에 너무 오래 걸림 & $\Rightarrow$ & 과제소요결정 후 단기간 내 착수 \\
\hline 간접비 비현실성 & - 기초연구사업비가 낮아 대부분 대학에서 수행하고 정출연 참여 곤란 & $\Rightarrow$ & \\
\hline 국방연구기관 배타성 & - ADD가 준비 중인 과제는 수행 곤란, ADD가 과제선정 권한 보유 & $\Rightarrow$ & 정출연 중점 연구분야 \\
\hline 과제관리 시 & · 개발 중 관리기관의 과다한 회의 소집 및 행정업무 처리 요구 & $\Rightarrow$ & 계약방식이 아닌 협약방식 적용 \\
\hline 참여정보 & - 국방분아에세서 필요로 하는 기술정보(내용, 시점 등) 부족(비밀사항이 많음) & $\Rightarrow$ & 갸 기술정보 공개 확대 \\
\hline 지식재산권 미보장 & - 지식재산권이 개발기란이 아닌 $A D D$ 로 귀속 & & (비영리기관과 공동소유 법제화 완료) \\
\hline 과제제안-수행주체 분리 & - 기술수요조사서를 제출히 & $\Rightarrow$ & 택 시 우선 선정 \\
\hline 민군협력체계 미흡 & 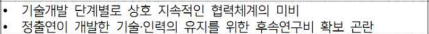 & $\Rightarrow$ & \\
\hline $\begin{array}{l}\text { 국방연구개발 방향성 } \\
\text { (기룰로댑ㅂㅂ) 제시흡 }\end{array}$ & - 기술가발로드맵 등에 대한 비콩개로 장기적 측면 참여계획 수립 곤란 & $\Rightarrow$ & 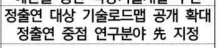 \\
\hline 연구내용이 정출연과 상이 : & 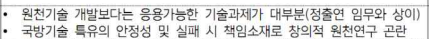 & $\Rightarrow$ & (성실실패제도 법제화 완료) \\
\hline 연구비 집행.정산 애로 & 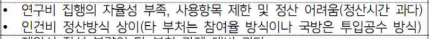 & $\Rightarrow$ & 계약방식이 아닌 협약방식 적용 \\
\hline 기타 & 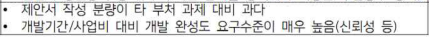 & & - \\
\hline
\end{tabular}

정출연의 국방연구개발 참여 및 보유기술의 군 이전이 촉진 될 수 있도록 (1) 국방획득 시 민간 정출연 보유기술 검토·활 용 제도화, (2) 정출연 등 보유기술 조사 정례화 및 활용 인프 라 마련, (3) 정출연 내 민군기술협력 인프라 구비의 3가지 개 선사항을 제시하였다.

7.1 국방획득 시 정출연 등 보유기술 검토·활용 제도화

무기체계 소요기획, 선행연구 등 국방획득 업무과정에서 정 출연 보유기술 정보 활용을 제도화하고, 국방부처 주도로 무기 체계 등 개발 시 활용될 수 있도록 다양한 Spin-On 방안 기 획·추진

\section{정출연의보유기술의 국방활용방안사례}

활용단계

무기체계소요기획시 ·합참방사청이무기체계소요에 대한 기술적검토시기존의 국방과학기술뿐만아니라

선행연구및사업추진 •방사청(초기IPT)이획득방안수립단계에서기술적요소의 일환으로 연구개발가능성검토, 기본전략수립 $\quad$ 부처간협력방안등을 수립하기위한 기반정보로서활용

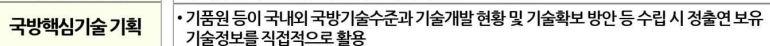

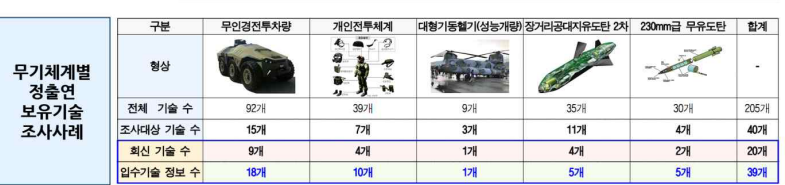

그림 4. 정출연의 보유기술의 국방 활용방안 사례

Fig. 4. Examples of defense utilization application plan of GSRI's possessed technologies

7.2 정출연 등 보유기술 조사 정례화 및 활용 인프라 마련 정출연 보유기술의 국방분야 활용이 원활하게 이루어질 수 있는 기반 인프라로서 국방기관-정출연간 기술정보 공유체계 를 마련하고 국방분야 기술료 제도 정비 등 사전준비 추진

\section{정출연보유기술조사및활용인프라마련}

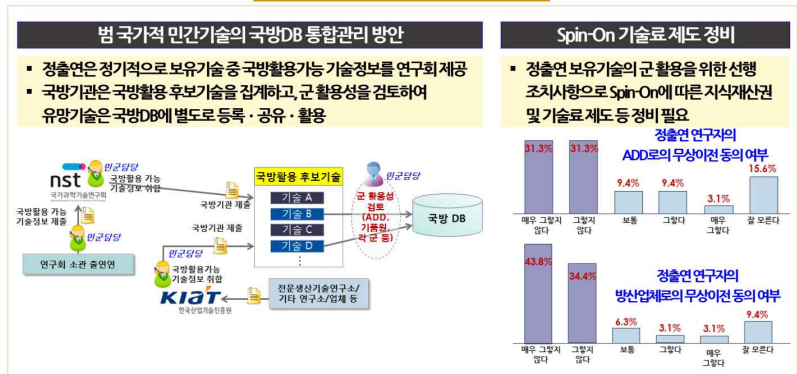

그림 5. 정출연 보유기술 조사 및 활용 인프라 마련

Fig. 5. Investigation of GSRI's possessed technologies and preparation for utilization infrastructure

\section{3 정출연 내 민군기술협력 인프라 구비}

정출연 기관 내 민군기술협력을 활성화할 수 있는 환경 및 인프라 구비 추진

\section{표 3. 정출연 내 민군기술협력 인프라 구비 과제}

Table 3. Civil-military technical cooperation infrastructure establishment projects in GSRI

정출연내민군기술협력인프라구비과제

\begin{tabular}{|c|c|c|}
\hline 괴제명 & 내용 & 비고 \\
\hline $\begin{array}{l}\text { 민군협력정담부서 } \\
\text { 운영 }\end{array}$ & 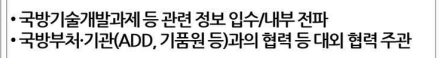 & $\begin{array}{l}\text { - KIST, 생명연, ETRI, } \\
\text { 기계연, 원자력연등 }\end{array}$ \\
\hline $\begin{array}{l}\text { 협력기술분야대상 } \\
\text { 자원투하확대 }\end{array}$ & 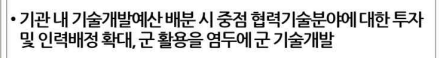 & $\begin{array}{l}\text { ·굳방부처 이외 과기정통부 } \\
\text { 등 R\&D 예산유치 }\end{array}$ \\
\hline $\begin{array}{c}\text { 국방활용유망기술정보 } \\
\text { 별도관리공유 }\end{array}$ & 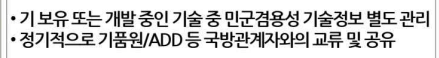 & $\begin{array}{l}\text { ·공개가는한기술은 } \\
\text { 국앙부처가 DTIMS에등록 }\end{array}$ \\
\hline $\begin{array}{l}\text { 방산업체등과의 } \\
\text { 협력 } 5 \text { 대 }\end{array}$ & $\begin{array}{l}\text { - 보유ㅁㅣㅣㄱ개발기술정보의 방산업체대상 정기적인공유 및 } \\
\text { 이전활동 활성화 }\end{array}$ & - 개발기술의 국방사업화 \\
\hline
\end{tabular}

\section{8. 정출연 협력방안}

정출연 고유 연구영역 특성을 고려하여볼때, 표준연 몇 전문 가들의 의견취합이 정출연 전체 의견으로 대변될 수는 없겠지 만 공통적인 의견들일 것으로 판단되며, 정출연 협력방안에 관 하여 제시하여본다.

\section{1 정출연 보유기술의 군 활용 촉진 관련}

8.1.1 정출연 기 개발 - 보유 민군겸용성 기술의 군 활용 저 해요인 
표 4. 정출연 보유 기술의 군사적 활용을 저해하는 요인

Table 4. Factors hindering the military utilization of GSRI's possessed technologies

\begin{tabular}{|c|c|}
\hline 구분 & 무기체계 적용 관점 \\
\hline $\begin{array}{c}\text { 핵심 } \\
\text { 걸림 } \\
\text { 돌 }\end{array}$ & $\begin{array}{l}\text { - 보유기술이 군에 사용될 것 같으나 무기체계에 } \\
\text { 대한 인식부족으로 군활용 연구참여를 꺼려함. } \\
\text { - 보안과 관련없는 단순기술의 경우에도 과도하게 } \\
\text { 보안과제로 분류되어 인적/정보인프라/ 등에 제 } \\
\text { 한이 있음 } \\
\text { - 정출연 기관은 비영리기관으로 국방기술개발사업 } \\
\text { 이 무기체계 적용, 방산업체의 사업화 수준으로 } \\
\text { 목표가 설정될 경우 과제수행이 어려움 }\end{array}$ \\
\hline
\end{tabular}

8.1.2 정출연 자체 투자 등에 의한 군 활용기술 개발 활성 화 방안

표 5. 정출연 투자를 통한 군사 활용 기술 개발 활성화 계획 Table 5. Plan to activate the development of military utilization technology by investing in GSRI

\begin{tabular}{|c|c|}
\hline 구분 & 무기체계 적용 관점 \\
\hline $\begin{array}{l}\text { 국방분야 } \\
\text { 개선사항 }\end{array}$ & $\begin{array}{l}\text { - 소요기술 제안이 될 경우 제안 기술에 대한 } \\
\text { 국내 개발 수준 및 추진 방향 등을 좀더 상 } \\
\text { 세히 제시해 주고 feedback을 해준다면 향 } \\
\text { 후 새로운 소요기술 도출하고 제안하는데 도 } \\
\text { 움이 될 것임 }\end{array}$ \\
\hline $\begin{array}{l}\text { 민간분야 } \\
\text { 개선사항 }\end{array}$ & $\begin{array}{l}\text { - 정출연에서는 국방기술을 지원할 수 있는 부 } \\
\text { 서나 센터를 활성화하고 연구예산확보에도 } \\
\text { 주력하도록하며, 특히 군에서 필요한 시험평 } \\
\text { 가기술은 다양하므로 출연연 시험연구센터 } \\
\text { 설립이 필요함 }\end{array}$ \\
\hline
\end{tabular}

8.2 정출연과 국방관계자 간 상시적 협력모델 구축 관련 8.2.1 출연연과 각 군과의 협력 저해요인 또는 핵심 개선항 목

표 6. 정출연과 군간 협력의 방해 요소 또는 주요 개선 항목 Table 6. Hindrance factors or key improvement items of cooperation between GSRI and military

\begin{tabular}{|c|c|}
\hline 구분 & 정출연 내부 사항 \\
\hline $\begin{array}{c}\text { 핵심 걸림돌 } \\
\text { 또는 } \\
\text { 개선항목 }\end{array}$ & $\begin{array}{l}\text { - 국방기술개발 내용이 포함된 사업 자체 } \\
\text { 지원 예산이 거의 전무함 }\end{array}$ \\
\hline
\end{tabular}

8.2.2 정출연과 $\mathrm{ADD}$ 와의 협력 저해요인 또는 핵심 개선항 목

표 7. 정출연과 $\mathrm{ADD}$ 협력의 장애 요인 또는 주요 개선 사항 Table 7. Hindrance factors or key improvement items of cooperation between GSRI and ADD

\begin{tabular}{|c|c|}
\hline 구분 & \multicolumn{1}{|c|}{ 정출연 내부 사항 } \\
\hline & $\bullet \begin{array}{l}\text { 정출연에 국방관련 연구센터를 운영하여 } \\
\text { 연구과제의 홍보 및 과제 도출을 계획적 }\end{array}$ \\
$\begin{array}{c}\text { 핵심 걸림돌 } \\
\text { 또는 } \\
\text { 개선항목 }\end{array}$ & $\begin{array}{l}\text { 으로 할 수 있도록 지원함 } \\
\text { 정출연간의 상호연대를 지원할 수 있는 } \\
\text { 협력센터를 운영함 }\end{array}$ \\
\hline
\end{tabular}

8.2.3 정출연과 방산분야 업체와의 협력 저해요인 또는 핵 심 개선항목

표 8. 정출연과 한국 방위 산업 협력의 장애 요인 또는 주요 개선 사항

Table 8. Hindrance factors or key improvement items of cooperation between GSRI and Korea defense industries

\begin{tabular}{|c|c|}
\hline 구분 & 출연연 내부 사항 \\
\hline $\begin{array}{c}\text { 핵심 걸림돌 } \\
\text { 또는 } \\
\text { 개선항목 }\end{array}$ & $\begin{array}{l}\text { - 기관 고유업무 과다, 국방 관련기술에 } \\
\text { 대한 경험 부족으로 과제 수주에 미온 } \\
\text { 적이며, 여러 가지 행정적 번거로움과 } \\
\text { 사후관리가 복잡해서 방산업체와의 연 } \\
\text { 구협력이나 수탁과제 수행을 꺼려함 }\end{array}$ \\
\hline
\end{tabular}

\section{9. 결 론}

2021년도 민·군기술협력사업 시행계획을 확정·발표에 따르면, 21년부터는 알키미스트(산업부), 미래도전국방기술개발(방사청) 등 도전·혁신적 국가 $\mathrm{R \& D}$ 신기술을 민군기술협력사업과 적극 연계하며, 국방분야 활용(Spin-on)을 통해 실증기록 (Trackrecord)을 확보해 나가고 4차 산업혁명 민간 우수기술 의 국방적용(Spin-on)을 신속히 지원할 예정이다. 이에 무엇 보다도 정출연의 역할 및 적극적인 동참이 더욱 중요해지고 있다.

그간 부처 간 업무협약 체결, 연구기관 간 협의체 구성 등 협업 기반을 마련하였으며, 국가R\&D의 과학기술 혁신과 국방 $\mathrm{R} \& \mathrm{D}$ 의 국방역량 확보 사이의 칸막이를 제거( 현재의 국가-국 방 R\&D 시스템 하에서 두 체계의 연계를 강화)하여, 국방과학 기술의 질적향상을 높이는 연구개발 체계를 마련하기 위해 협력을 지속해 왔다.

민군기술협력을 위한 정책적 지원과 협력 필요성에 대한 공 감대가 내실적으로 형성되어야 하며, 민군기술협력의 관건은 '수요' 확보에 따라 '기술' 중심으로 접근을 해야 효과적이기 때문에, 국방 $\mathrm{R \& D}$ 의 진입장벽을 해소하며 민간 첨단기술이 국방 분야에 활발히 접목될 수 있는 환경이 조성되어야 한다. 
민군기술협력은 현재 이원화되어 있는 국가R\&D 수행체계와 국방R\&D 수행체계를 상호 연계하는 제반 활동으로 구성되어 있기 때문에 사업 기획단계부터 개발성과물의 등록·관리 단계 까지 연구개발사업 전 순기적으로 양자 간 민군기술협력이 활 성화될 경우 상호 시너지 효과를 극대화할 수 있다

한정된 국방R\&D 예산하에 일류 국방과학기술과 선진 국방력 확보를 위해서는 민간의 기술을 효과적으로 방위산업에 끌어 들일 수 있는 전략이 중요하여 정출연 보유기술의 군 적용 활 성화 방안 등이 제안되었고, 정출연의 국방과학기술을 발전시 키는 역할 담당이 상당히 중요하게 요구되고 있는 실정이다.

아직까지 무기체계 개발과정에서 우수하고 충분히 성숙되어 있는 정출연 보유기술들이 알차게 활용되지 못하는 문제점들 이 있기는 하지만, 이것들이 조속히 원활하게 해결되어 정출연 이 민간기술의 무기체계 등 군 활용을 촉진하는 역할을 하여 자주국방 역량 강화와 국가경제 성장 기여 등 다양한 파급효 과를 창출할 수 있는 국방과학기술 발전에 일익을 담당하여야 할 것이다.

\section{References}

[1] 김기완, 김 진, 신진교, 홍성범, “정부 $\mathrm{R} \& \mathrm{D}$ 투자의 효율성 제고방안 연구" 한국개발연구원(KDI), 12. 2011

[2] “과학기술기반 미래 국방력 강화”, 2018 글로벌 기계기술 포럼, 9. 2018

[3] H. Yoo, and D. Chang, "A Study on the Military Application of technologies possessed Private research institute," Autumn Conference, 0-08, 2019 